\title{
Cerclage retention versus removal following preterm premature rupture of membranes and association with amniotic fluid markers
}

\author{
Eduardo Aguin ${ }^{\mathrm{a}, *}$, Cosmas Van De Ven ${ }^{\mathrm{a}}$, Marcos Cordoba ${ }^{\mathrm{b}}$, Samet Albayrak ${ }^{\mathrm{c}}$, Ray Bahado-Singh ${ }^{\mathrm{d}}$ \\ a Department of Obstetrics and Gynecology, Division of Maternal Fetal Medicine, University of Michigan, Ann Arbor, USA \\ b Department of Obstetrics and Gynecology, Division of Maternal Fetal Medicine, New York University, New York, USA \\ c Department of Obstetrics and Gynecology, Wayne State University, Detroit, USA \\ d Department of Obstetrics and Gynecology, Oakland University - William Beaumont Hospital School of Medicine, Royal Oak, USA
}

\section{A R T I C L E I N F O}

\section{Article history:}

Received 7 July 2013

Received in revised form 4 October 2013

Accepted 23 December 2013

\section{Keywords:}

Amniocentesis

Cerclage

Infection

Inflammation

Outcome

Prematurity

Preterm premature rupture of membranes

Ultrasound

\begin{abstract}
A B S T R A C T
Objective: To evaluate whether amniotic fluid markers can aid the decision of whether to retain or remove a cervical cerclage after preterm premature rupture of membranes (PPROM). Methods: A retrospective cohort study included pregnancies involving PPROM after diagnostic amniocentesis and cerclage placement. Cerclage was retained for more than 12 hours after PPROM in the study group $(n=18)$; the comparison group comprised women who underwent immediate cerclage removal after PPROM $(\mathrm{n}=22)$. Analyses were performed using concentrations of interleukin (IL)-6, glucose, and white blood cells (WBCs) in the amniotic fluid to measure relationships with adverse outcomes. Results: The latency period from PPROM to delivery was significantly shorter in the group that underwent immediate cerclage removal $(P<0.005)$. Latency periods of more than 48 hours $(P<0.001)$ and more than 7 days $(P<0.01)$, and chorioamnionitis $(P<0.05)$ were associated with cerclage retention. Neonatal outcomes were not significantly different between the study group and the comparison group. However, elevated IL-6 levels were associated with cumulative neonatal morbidity $(P<0.05)$. Low IL-6 $(P<0.001)$ and WBC $(P<0.05)$ levels were significantly associated with a latency period of more than 7 days. Conclusion: Amniotic fluid levels of IL-6 and WBCs may be of clinical value for individualizing the management of patients with PPROM after cerclage.
\end{abstract}

Published by Elsevier Ireland Ltd. on behalf of International Federation of Gynecology and Obstetrics.

\section{Introduction}

Cervical cerclage is a procedure performed worldwide to improve outcomes in settings involving prematurity. Preterm premature rupture of membranes (PPROM) is a common complication that has been reported in $38 \%$ of patients with a cervical cerclage in place [1]. The potential benefit of cerclage retention-which prolongs the latency period between PPROM and delivery, and decreases complications related to prematurity-must be balanced with the risk of adverse neonatal outcomes related to infection. Although cerclage is used in only $0.4 \%$ of pregnancies in the USA [2], $11.4 \%$ of patients with a diagnosis of PPROM have a cerclage in place [3]. The management of PPROM is relatively well established in the absence of cerclage but limited data are available from studies regarding the management of PPROM when a cerclage is in place. Controversy remains regarding the decision on whether to retain the cerclage or remove it. Some studies have shown increased intrauterine infection risks and increased neonatal morbidity with cerclage retention [4,5], while others have not demonstrated such a difference in maternal and perinatal outcomes, supporting prolonged latency with cerclage retention after PPROM [6,7]. These conflicting results indicate the need for a more individualized intervention on a caseby-case basis among patients with PPROM after cerclage placement.

Inflammatory markers in amniotic fluid are predictive of neonatal outcomes in cases of preterm labor with intact membranes. The data are more limited regarding the significance of such markers in cases of PPROM [8]. In a previous study, we analyzed the association of amniotic fluid markers with success rates of cervical cerclage [9]. The aim of the present study was to evaluate whether amniocentesis plus measurement of amniotic fluid markers can aid in the decision to retain or remove a cervical cerclage after PPROM. We hypothesized that the concentration of inflammatory markers-including interleukin (IL)-6, glucose, and white blood cells (WBCs)-in amniotic fluid can be used to distinguish cases that would benefit from retaining or removing the cerclage in the presence of PPROM.

* Corresponding author at: Department of Obstetrics and Gynecology, Division of Maternal Fetal Medicine, University of Michigan, Von Voigtlander Women's Hospital, 1500 E. Medical Center Dr., SPC 5276, Ann Arbor, MI 48109, USA. Tel.: +1 248224 3808; fax: +1 7346471006 .

E-mail addresses: eaguin@med.umich.edu, eaguin@hotmail.com (E. Aguin).

\section{Materials and methods}

A retrospective cohort study was conducted involving women who presented with PPROM after diagnostic amniocentesis and cervical 
cerclage placement. Women were eligible for inclusion if they had undergone amniocentesis within 3 days prior to ultrasound-indicated cerclage placement between January 1, 2008, and December 31, 2011, at Hutzel Women's Hospital at the Detroit Medical Center/Wayne State University, Detroit, MI, USA, and subsequently presented with a diagnosis of PPROM. The institutional review board at Wayne State University approved the analysis before the study began. Informed consent was obtained when the procedures were performed.

Data were abstracted based on a review of paired obstetric and neonatal medical records. The study group consisted of women in whom the cerclage was retained for more than 12 hours after PPROM; the comparison group comprised women who underwent immediate cerclage removal after PPROM.

Amniocentesis was performed secondary to risk factors for preterm birth, such as short cervix, preterm labor contractions, and previous preterm history. In all patients, cerclage placement was performed because of ultrasound-indicated shortening of the cervix (defined as cervical length $<25 \mathrm{~mm}$ with a history of preterm birth) [10,11].

Amniotic fluid specimens were sent for Gram staining; mycoplasmic, aerobic, and anaerobic bacteria cultures; and WBC, glucose, and IL-6 concentration assays to rule out infection and/or inflammation. Rescue cervical cerclage was performed between 17 and 23 weeks of gestation. McDonald cerclage was performed in all cases, using a 5-mm nonabsorbable polyester suture (Mersilene; Ethicon, Somerville, NJ, USA) in the cervical-vaginal junction [12]. None of the patients received antibiotics prior to amniocentesis or at the time of cerclage. Diagnosis of PPROM was via direct visualization of fluid (pooling) in the posterior vaginal fornix during sterile speculum examination, together with positive confirmatory tests (e.g. nitrazine test) on cervicovaginal swab, presence of arborization (ferning), and ultrasonographic diagnosis of oligohydramnios [13]. Patients received antibiotics after 24 weeks of pregnancy to prolong latency periods and provide fetal benefits $[14,15]$. Betamethasone for fetal lung maturity was administered at 24-32 weeks for patients with PPROM or imminent risk of preterm delivery [16,17]. 17 $\alpha$-Hydroxyprogesterone caproate was started at 16-20 weeks in all women with prior preterm birth for the prevention of prematurity $[18,19]$. Tocolytics and transabdominal amnioinfusion were not administered.

The outcomes addressed were latency period from PPROM to delivery, histologic chorioamnionitis, gestational age at time of delivery, latency period of more than 48 hours after PPROM, latency period of more than 7 days after PPROM, perinatal mortality, neonatal birth weight, neonatal sepsis, and cumulative neonatal morbidity. Cumulative neonatal morbidity was defined as sepsis, respiratory distress syndrome, pneumonia, bronchopulmonary dysplasia, intraventricular hemorrhage, or necrotizing enterocolitis.

Statistical analyses were performed using SPSS version 17.0 (IBM, Armonk, NY, USA). The $t$ test, $\chi^{2}$ test, and Spearman correlation coefficient were used in the statistical analysis. $P<0.05$ was considered to be statistically significant.

\section{Results}

The total study population for clinically indicated amniocentesis and cerclage included 127 cases. There were 87 exclusions: 55 patients did not have a clear diagnosis of PPROM; 2 patients had positive amniotic fluid cultures; 11 patients had twin or multiple pregnancies; and placental histology was absent for 19 patients. The remaining 40 cases involved singleton pregnancies with negative amniotic fluid cultures and subsequent cerclage placement followed by PPROM. The study group consisted of 18 women with retained cerclage; the comparison group consisted of 22 women who underwent immediate cerclage removal.

The 2 groups were similar in terms of the selected demographic characteristics (Table 1), and the data were normally distributed. There were 36 African American patients, 3 white patients, and 1 Hispanic patient. The 2 groups had similar concentrations of inflammatory markers in amniotic fluid (Table 2). Cerclage retention was associated with a latency
Table 1

Demographic characteristics. $^{a}$

\begin{tabular}{lrrr}
\hline Characteristic & \multicolumn{1}{c}{$\begin{array}{l}\text { Removal } \\
(\mathrm{n}=22)\end{array}$} & \multicolumn{1}{c}{$\begin{array}{l}\text { Retention } \\
(\mathrm{n}=18)\end{array}$} & Pvalue \\
\hline Maternal age, $\mathrm{y}$ & $26.41 \pm 5.09$ & $28.50 \pm 5.58$ & 0.224 \\
Gravidity (per patient) & $3.50 \pm 2.04$ & $3.83 \pm 1.79$ & 0.591 \\
Full-term parity (per patient) & $0.18 \pm 0.50$ & $0.17 \pm 0.38$ & 0.917 \\
Previous preterm delivery (per patient) & $1.77 \pm 1.11$ & $2.06 \pm 1.16$ & 0.437 \\
Gestational age at time of cerclage, wk & $20.19 \pm 2.32$ & $19.96 \pm 1.72$ & 0.725 \\
Gestational age at time of amniocentesis, wk & $19.87 \pm 2.42$ & $19.54 \pm 2.05$ & 0.655 \\
Gestational age at time of PPROM, wk & $27.23 \pm 5.33$ & $26.94 \pm 5.01$ & 0.858 \\
Maternal body mass index & $34.53 \pm 8.05$ & $31.68 \pm 8.64$ & 0.290 \\
Maternal cervical length, mm & $14.07 \pm 10.50$ & $12.82 \pm 11.74$ & 0.717 \\
\hline
\end{tabular}

Abbreviation: PPROM, preterm premature rupture of membranes.

${ }^{\text {a }}$ Values are given as mean \pm SD unless otherwise indicated.

b Calculated as weight in kilograms divided by the square of height in meters.

period of more than 48 hours $(61.1 \%$ in the study group vs $9.1 \%$ in the comparison group; relative risk [RR] 6.7; 95\% confidence interval [CI], 1.6-9.4; $P<0.001)$; a latency period of more than 7 days $(31.7 \%$ vs 2.5\%; RR 12.6; 95\% Cl, 1.7-24.1; $P<0.01)$; and chorioamnionitis $(99.9 \%$ vs $59.1 \%$; RR $1.7 ; 95 \% \mathrm{CI}, 1.4-3.1 ; P<0.05)$. The latency period from PPROM to delivery was significantly shorter in the removal group than in the retention group $(P<0.005)$ (Table 3$)$. There were no significant differences between the groups in the other pregnancy and neonatal outcomes (Table 4).

A sub-analysis of the relationship between inflammatory markers in amniotic fluid and pregnancy/neonatal outcomes revealed that high IL-6 concentrations were associated with a higher risk of cumulative neonatal morbidity (50\% in presence of cumulative neonatal morbidity vs $1 \%$ in absence; RR 50; 95\% CI, 14.2-66.5; $P<0.05$ ) (Table 5). Low IL-6 concentrations were associated with a latency period of more than 7 days $(21.7 \%$ in presence of latency period $>7$ days vs $2.5 \%$ in absence; RR 8.7; 95\% CI, 2.4-12.6; $P<0.001)$, as were low WBC concentrations ( $87.5 \%$ in presence of latency period $>7$ days vs $12.5 \%$ in absence; RR 7 ; 95\% CI, 4.02-11.6; $P<0.05$ ). There were no other significant associations between pregnancy/neonatal outcomes and concentrations of inflammatory markers in amniotic fluid (Table 6).

\section{Discussion}

The acute management of PPROM in the absence of indications for delivery is expectant and requires the use of latency antibiotics to prolong pregnancy and reduce neonatal morbidity [20]. However, the

Table 2

Concentration of inflammatory markers in amniotic fluid.

\begin{tabular}{llcl}
\hline Marker & Removal $(\mathrm{n}=22)$ & Retention $(\mathrm{n}=18)$ & $P$ value \\
\hline Interleukin-6, $\mathrm{ng} / \mathrm{mL}$ & $26.14 \pm 33.52$ & $17.64 \pm 26.38$ & 0.387 \\
White blood cells, cells $/ \mathrm{mm}^{3}$ & $21.00 \pm 28.23$ & $8.39 \pm 17.20$ & 0.106 \\
Glucose, $\mathrm{mg} / \mathrm{dL}$ & $36.45 \pm 24.93$ & $30.78 \pm 7.39$ & 0.358 \\
\hline
\end{tabular}

${ }^{\text {a }}$ Values are given as mean \pm SD unless otherwise indicated.

Table 3

Pregnancy outcomes. ${ }^{\mathrm{a}}$

\begin{tabular}{lllr}
\hline Outcome & Removal $(\mathrm{n}=22)$ & Retention $(\mathrm{n}=18)$ & $P$ value \\
\hline $\begin{array}{l}\text { Gestational age at time of } \\
\quad \text { delivery, wk }\end{array}$ & $27.19 \pm 5.32$ & $25.68 \pm 7.09$ & 0.349 \\
$\begin{array}{l}\text { Latency period from PPROM } \\
\quad \text { to delivery, } \mathrm{C}\end{array}$ & $0.64 \pm 1.43$ & $6.50 \pm 7.09$ & 0.003 \\
$\begin{array}{l}\text { Latency period of }>48 \text { hours } \\
\text { Latency period of }>7 \text { days }\end{array}$ & $2(9.1)$ & $11(61.1)$ & $<0.001$ \\
Histologic chorioamnionitis & $13(59.1)$ & $6(31.7)$ & 0.008 \\
\hline
\end{tabular}

Abbreviation: PPROM, preterm premature rupture of membranes.

${ }^{\text {a }}$ Values are given as mean \pm SD or number (percentage) unless otherwise indicated. 
Table 4

Neonatal outcomes. ${ }^{\mathrm{a}}$

\begin{tabular}{lccl}
\hline Outcome & Removal $(\mathrm{n}=22)$ & Retention $(\mathrm{n}=18)$ & $P$ value \\
\hline Birth weight, g & $1147.18 \pm 832.1$ & $903.72 \pm 575.4$ & 0.300 \\
Perinatal mortality & $10(45.4)$ & $9(50.0)$ & 0.775 \\
Cumulative neonatal morbidity & $7(31.8)$ & $5(27.7)$ & 0.952 \\
Neonatal sepsis & $5(22.7)$ & $3(16.6)$ & 0.891 \\
\hline
\end{tabular}

${ }^{a}$ Values are given as mean \pm SD or number (percentage) unless otherwise indicated.

Table 5

Sub-analysis of relationship between concentration of inflammatory markers in amniotic fluid and neonatal outcomes. ${ }^{\text {a }}$

\begin{tabular}{|c|c|c|c|}
\hline Outcome & $\begin{array}{l}\text { Interleukin-6, } \\
\mathrm{ng} / \mathrm{mL}\end{array}$ & $\begin{array}{l}\text { White blood cells, } \\
\text { cells } / \mathrm{mm}^{3}\end{array}$ & $\begin{array}{l}\text { Glucose, } \\
\mathrm{mg} / \mathrm{dL}\end{array}$ \\
\hline \multicolumn{4}{|l|}{ Perinatal mortality } \\
\hline Present $(\mathrm{n}=19)$ & $31.45 \pm 23.9$ & $23.45 \pm 15.3$ & $29.56 \pm 35.2$ \\
\hline Absent $(\mathrm{n}=21)$ & $17.64 \pm 26.3$ & $21.6 \pm 18.21$ & $30.15 \pm 29.9$ \\
\hline$P$ value & 0.891 & 0.766 & 0.862 \\
\hline \multicolumn{4}{|c|}{ Cumulative neonatal morbidity } \\
\hline Present $(\mathrm{n}=12)$ & $34.35 \pm 44.3$ & $25.33 \pm 29.6$ & $26.51 \pm 18.9$ \\
\hline Absent $(\mathrm{n}=28)$ & $0.92 \pm 0.859$ & $17.45 \pm 37.8$ & $29.95 \pm 24.9$ \\
\hline$P$ value & 0.018 & 0.284 & 0.446 \\
\hline \multicolumn{4}{|l|}{ Neonatal sepsis } \\
\hline Present $(\mathrm{n}=8)$ & $28.15 \pm 27.1$ & $31.23 \pm 17.3$ & $29.56 \pm 35.5$ \\
\hline Absent $(\mathrm{n}=32)$ & $21.78 \pm 26.1$ & $29.76 \pm 19.2$ & $34.01 \pm 30.1$ \\
\hline$P$ value & 0.375 & 0.798 & 0.630 \\
\hline
\end{tabular}

a Values are given as mean \pm SD unless otherwise indicated.

clinical significance of cerclage retention and its impact on outcomes after PPROM has yet to be properly evaluated.

In their 2010 systematic review, Walsh et al. [21] reported that the benefits of retaining a cerclage in situ with a ruptured membrane were unclear. However, the review was based on a few relatively small retrospective and underpowered studies (level II evidence).

In 2011, Giraldo-Isaza and Berghella [22] published a review of the existing literature, comparing retention and removal of cervical cerclage after PPROM. The authors concluded that cerclage retention for more than 24 hours after PPROM prolonged pregnancy for more than 48 hours but also increased maternal chorioamnionitis and neonatal mortality from sepsis, making immediate cerclage removal preferable in most cases as a therapeutic approach. The authors also recommended the use of steroids for expediting fetal maturity before cerclage removal between 24 and $33+6$ weeks of gestation. The most interesting proposed management was the use of amniocentesis to rule out infection.

The goal of the present study was to determine whether amniocentesis could aid the clinical decision of whether to remove or retain a

Table 6

Sub-analysis of relationship between concentration of inflammatory markers in amniotic fluid and pregnancy outcomes. ${ }^{\text {a }}$

\begin{tabular}{|c|c|c|c|}
\hline Outcome & $\begin{array}{l}\text { Interleukin-6, } \\
\mathrm{ng} / \mathrm{mL}\end{array}$ & $\begin{array}{l}\text { White blood cells, } \\
\text { cells } / \mathrm{mm}^{3}\end{array}$ & $\begin{array}{l}\text { Glucose, } \\
\mathrm{mg} / \mathrm{dL}\end{array}$ \\
\hline \multicolumn{4}{|c|}{ Latency period of $>48$ hours after PPROM } \\
\hline Present $(n=13)$ & $21.32 \pm 26.4$ & $16.07 \pm 19.2$ & $31.35 \pm 10.1$ \\
\hline Absent $(\mathrm{n}=27)$ & $23.04 \pm 28.3$ & $25.6 \pm 21.2$ & $29.1 \pm 20.8$ \\
\hline$P$ value & 0.891 & 0.065 & 0.698 \\
\hline \multicolumn{4}{|c|}{ Latency period of $>7$ days after PPROM } \\
\hline Present $(n=7)$ & $0.70 . \pm 0.45$ & $4.80 \pm 6.611$ & $30.5 \pm 14.9$ \\
\hline Absent $(\mathrm{n}=33)$ & $25.41 \pm 31.4$ & $21.83 \pm 25.6$ & $38.45 \pm 24.4$ \\
\hline$P$ value & $<0.001$ & 0.031 & 0.521 \\
\hline \multicolumn{4}{|c|}{ Histologic chorioamnionitis } \\
\hline Present $(\mathrm{n}=8)$ & $20.1 \pm 10.9$ & $34.8 \pm 15.4$ & $30.3 \pm 9.23$ \\
\hline Absent $(\mathrm{n}=32)$ & $12.72 \pm 38.2$ & $29.62 \pm 23.2$ & $32.8 \pm 21.5$ \\
\hline$P$ value & 0.062 & 0.073 & 0.689 \\
\hline
\end{tabular}

Abbreviation: PPROM, preterm premature rupture of membranes.

${ }^{\text {a }}$ Values are given as mean \pm SD unless otherwise indicated. cerclage after PPROM. In the present study, cerclage retention prolonged the latency period after PPROM but it did not have a significant effect on neonatal outcome. However, sub-analysis revealed that elevated amniotic IL-6 concentrations were associated with neonatal morbidity and that low amniotic IL-6 and WBC concentrations were associated with a latency period of more than 7 days.

The limitations of the present study were its relatively small sample size and its retrospective nature, which increased the risk of bias.

In summary, the present results indicate that measurement of IL-6 and WBC levels in amniotic fluid may be of clinical value for individualizing the management of patients with PPROM after cervical cerclage placement. The results of the study solidify our previous recommendation [9] of amniocentesis prior to rescue cerclage because of the capacity of inflammatory markers in the amniotic fluid to identify patients who would benefit from cerclage and to detect subclinical infections that might otherwise compromise fetal status if PPROM occurred and the cerclage were retained. Furthermore, because the physiologies of uterine contractions and cervical shortening, as well as the techniques used for cerclage placement and amniocentesis, are similar among women of all races and ethnicities, the conclusions of the present study may be applicable globally.

\section{Conflict of interest}

The authors have no conflicts of interest.

\section{References}

[1] Treadwell MC, Bronsteen RA, Bottoms SF. Prognostic factors and complication rates for cervical cerclage: a review of 482 cases. Am J Obstet Gynecol 1991;165(3):555-8.

[2] Martin JA, Menacker F. Expanded health data from the new birth certificate, 2004. Natl Vital Stat Rep 2007;55(12):1-22.

[3] Laskin DM, Yinon Y, Whittle WL. Preterm premature rupture of membranes in the presence of cerclage: is the risk for intra-uterine infection and adverse neonatal outcome increased? J Matern Fetal Neonatal Med 2012;25(4):424-8.

[4] Ludmir J, Bader T, Chen L, Lindenbaum C, Wong G. Poor perinatal outcome associated with retained cerclage in patients with premature rupture of membranes. Obstet Gynecol 1994;84(5):823-6.

[5] Jenkins TM, Berghella V, Shlossman PA, McIntyre CJ, Maas BD, Pollock MA, et al. Timing of cerclage removal after preterm premature rupture of membranes: maternal and neonatal outcomes. Am J Obstet Gynecol 2000;183(4):847-52.

[6] Blickstein I, Katz Z, Lancet M, Molgilner BM. The outcome of pregnancies complicated by preterm rupture of the membranes with and without cerclage. Int J Gynecol Obstet 1989;28(3):237-42.

[7] McElrath TF, Norwitz ER, Lieberman ES, Heffner LJ. Management of cervical cerclage and preterm premature rupture of the membranes: should the stitch be removed? Am J Obstet Gynecol 2000;183(4):840-6.

[8] Cobo T, Palacio M, Martínez-Terrón M, Navarro-Sastre A, Bosch J, Filella X, et al. Clinical and inflammatory markers in amniotic fluid as predictors of adverse outcomes in preterm premature rupture of membranes. Am J Obstet Gynecol 2011; 205(2):126.e1-8.

[9] Aguin E, Aguin T, Cordoba M, Aguin V, Roberts R, Albayrak S, et al. Amniotic fluid inflammation with negative culture and outcome after cervical cerclage. J Matern Fetal Neonatal Med 2012;25(10):1990-4.

[10] Owen J, Hankins G, Iams JD, Berghella V, Sheffield JS, Perez-Delboy A, et al. Multicenter randomized trial of cerclage for preterm birth prevention in high-risk women with shortened midtrimester cervical length. Am J Obstet Gynecol 2009;201(4): 375.e1-8.

[11] Berghella V, Keeler SM, To MS, Althuisius SM, Rust OA. Effectiveness of cerclage according to severity of cervical length shortening: a meta-analysis. Ultrasound Obstet Gynecol 2010;35(4):468-73.

[12] Mcdonald IA. Suture of the cervix for inevitable miscarriage. J Obstet Gynaecol Br Emp 1957;64(3):346-50.

[13] ACOG practice bulletin. Premature rupture of membranes. Clinical management guidelines for obstetrician-gynecologists. Number 1, June 1998. American College of Obstetricians and Gynecologists. Int J Gynecol Obstet 1998;63(1):75-84.

[14] Kenyon S, Boulvain M, Neilson JP. Antibiotics for preterm rupture of membranes. Cochrane Database Syst Rev 2013;12:CD001058.

[15] Kenyon SL, Taylor DJ, Tarnow-Mordi W, ORACLE Collaborative Group. Broadspectrum antibiotics for preterm, prelabour rupture of fetal membranes: the ORACLE I randomised trial. ORACLE Collaborative Group. Lancet 2001;357(9261): 979-88.

[16] Mercer BM. Preterm premature rupture of the membranes. Obstet Gynecol 2003;101(1):178-93. 
[17] Harding JE, Pang J, Knight DB, Liggins GC. Do antenatal corticosteroids help in the setting of preterm rupture of membranes? Am J Obstet Gynecol 2001;184(2):131-9.

[18] Petrini JR, Callaghan WM, Klebanoff M, Green NS, Lackritz EM, Howse JL, et al Estimated effect of 17 alpha-hydroxyprogesterone caproate on preterm birth in the United States. Obstet Gynecol 2005;105(2):267-72.

[19] Society for Maternal Fetal Medicine Publications Committee. ACOG Committee Opinion number 419 October 2008 (replaces no. 291, November 2003). Use of progesterone to reduce preterm birth. Obstet Gynecol 2008;112(4):963-5.
[20] Kenyon S, Taylor DJ, Tarnow-Mordi WO, ORACLE Collaborative Group. ORACLEantibiotics for preterm prelabour rupture of the membranes: short-term and longterm outcomes. Acta Paediatr Suppl 2002;91(437):12-5.

[21] Walsh J, Allen VM, Colford D, Allen AC. Preterm prelabour rupture of membranes with cervical cerclage: a review of perinatal outcomes with cerclage retention. J Obstet Gynaecol Can 2010;32(5):448-52.

[22] Giraldo-Isaza MA, Berghella V. Cervical cerclage and preterm PROM. Clin Obstet Gynecol 2011;54(2):313-20. 